\section{Una Historia en construcción}

\section{Historia cultural desde Colombia. Categorías y debates}

MAX S. HERING TORRES

Y AMADA C. PÉREZ BENAVIDES

(Editores)

Universidad Nacional de Colombia,

Pontificia Universidad Javeriana,

Universidad de los Andes, Bogotá,

20I2, 5 I9 págs., il.

DESDE LA década del ochenta del siglo XX al presente se ha abierto camino una corriente histórica: la historia de la cultura, que como lo plantea Mauricio Archila en su ensayo, se inició después de la "nueva revolución francesa" de mayo de I968, cuando las máximas de "Prohibido prohibir" y "la imaginación al poder" fracasaron, pero se produjeron nuevas rupturas y planteamientos, así como una verdadera diáspora epistemológica y metodológica. La historia cultural es entendida como la red de significaciones, imaginarios y representaciones, entroncadas con las relaciones y prácticas de poder, lo que amplió infinitamente el universo de análisis e interpretación de la historia a temáticas como la del cuerpo, el género, la cotidianidad, la prostitución, la vida privada, los sentidos, etc., en intima relación interdisciplinaria con otras ciencias humanas y sociales como la antropología, la lingüística, la semiótica, la geografía y la sociología, con énfasis en lo popular, en los de "abajo", en la otredad y en las minorías. La historia cultural así entendida ha ido creciendo cada vez más, en ello tiene mucho que ver el "derrumbe" del socialismo clásico, y con él la búsqueda de nuevos marcos teóricos diferentes al marxismo. Las fuentes de análisis se han multiplicado, ya no solo los documentos de archivo, los periódicos y la historia oral forman parte del acervo documental del historiador, ahora la iconografía, el cine, la literatura, la música, etc., han ampliado la base empírica de análisis. De igual manera, la forma de escribir la historia ha variado, se ha hecho más literaria, menos rigurosa, más imaginativa, pero, también, muy especulativa.

En Colombia, la historia cultural comenzó con timidez por los años ochenta y ha hecho cierto camino, en parte sustentada por la neoliberal, manipulada y remendada Constitución de I99I, en la que se dio licencia a lo pluriétnico y a lo multicultural. $\mathrm{Su}$ crecimiento ha sido significativo, de hecho el número de simposios en los últimos dos congresos colombianos de historia (20I0 y 20I2) es importante, aunque en algunos casos son demasiado cerrados, por lo general su organización corre a cargo de un grupo de investigación, se socializa entonces el resultado de sus propias investigaciones, no tratan de confrontar sus experiencias con los de temáticas concomitantes y pese a lo espectacular y atrayente de sus títulos, no alcanzan a llenar auditorios. Asimismo, como bien lo presenta Renzo Ramírez en su ensayo [págs. 37 I-373], el número de grupos registrados en Colciencias en el 20 Io que investigan sobre historia cultural es el mayor, alcanza veintitrés, el I5,97\%, de un número igual de énfasis disciplinares, que suman ciento cuarenta y cuatro en total. Sumado a ello, se han abierto algunas maestrías en Estudios Culturales, en universidades públicas y privadas, lo que sin duda ha contribuido a que la historia cultural haya superado el ser una moda.

No obstante, lo cierto del asunto es que la historia cultural, por lo menos en nuestro país, sigue siendo una corriente en construcción, de allí que Max S. Hering Torres y Amada Carolina Pérez Benavides, editores del libro Historia cultural desde Colombia. Categorías y debates, se hubiesen metido en la aventura, con el apoyo de tres de las principales universidades del país: la Nacional, la Javeriana, y los Andes, de adelantar un balance centrado en las categorías analíticas, relacionadas con el problema de la significación: prácticas, imaginarios y representaciones, tratando de mostrar su operatividad. Como los editores lo mencionan en las primeras líneas de los agradecimientos, la idea del libro "nació en un sitio en donde suelen surgir toda clase de ideas, menos la de editar un libro; bueno, por lo menos eso se supone... Demasiado ruido y fandango para pensar en un proyecto académico; o tal vez fue precisamente este ambiente el que nos hizo aven- turarnos en una propuesta colectiva". Al respecto debo decir que no es la primera ni única vez que esta clase de trabajos nacen en ambientes de rumba y festejo, por ejemplo, según recuerdo, la Historia de Antioquia nació en Santa Rosa de Osos, al calor de unos aguardientes, con motivo del centenario del nacimiento de Porfirio Barba Jacob, en una charla entre Jorge Orlando Melo y Nicanor Restrepo.

El libro, craneado y editado por Hering Torres y Pérez Benavides, pertenecientes al Grupo de Investigación Prácticas Culturales, Imaginarios y Representaciones (categoría A I de Colciencias), está organizado en una introducción, dos partes ("Categorías", dividida en prácticas, imaginarios y representaciones, con un total de nueve ensayos; "Debates", con siete ensayos) y un epílogo. Los diecisiete escritos fueron encargados a catorce autores principales, cinco mujeres y nueve hombres, la mayoría de ellos doctores en diferentes centros universitarios de Colombia, América Latina, Norteamérica y Europa, lo que permite una diversidad de tradiciones académicas; la mayoría de los autores poseen una destacada producción intelectual, no siempre orientada en el tema central del libro.

La introdución, a cargo de los editores, presenta el objetivo del libro, establece una diferencia entre analizar la cultura y hacer historia cultural, adelanta un ligero cuadro sobre el desarrollo de la historia cultural en Colombia y defiende su trasegar a contrapelo de las críticas, y realiza algunas consideraciones sobre historia cultural, a partir de algunos autores extranjeros y obras más representativas; marca diferencias con la historia social, económica y política, para, al final, presentar los ensayos que forman parte del libro. No sé hasta dónde sea válido plantear que "la historia cultural se la ha pensado desde un contexto colombiano" [pág. I9], pues, por lo que aparece en la introducción, los editores conocen ligeramente el trasegar de la historiografía colombiana, aunque sí es evidente que hubo un juicioso trabajo de análisis y estudio colectivo de las categorías analíticas.

La primera parte ratifica una aparente virtud de la historia cultural, pero muy criticada, en ella cabe cualquier época y temática, por lo que los nueve 
ensayos abarcan desde el Virreinato en la Colonia hasta finales del siglo XX, pero sin tocar el siglo XIX. Ocho de ellos analizan casos colombianos de corta duración, uno solo, el del profesor Paolo Vignolo, se centra en un caso europeo. En general, se ratifica la experiencia y tradición investigativa y analítica de María Victoria Uribe Alarcón y Jaime Humberto Borja Gómez, que desde finales de la década del ochenta, en el caso de Uribe, y desde la de finales del noventa, en el de Borja, han investigado y publicado temas relacionados con la historia cultural, en especial en lo atinente a prácticas, imaginarios y representaciones. Los seis autores restantes: Max S. Hering Torres, Soraya Maite Yie Garzón, Óscar Iván Salazar Arenas, Yobenj Aucardo Chingana-Bayona, Amada Carolina Pérez Benavides y Óscar Guarín Martínez poseen una característica en común, nacieron entre I 968 y I976, y su formación académica e intelectual data de la época de la caída del muro de Berlín al presente, lo que quizá permite entender su "apasionamiento" por la historia cultural, para ellos la apremiante necesidad de escribir una historia universitaria y profesional, a contrapelo de la Academia Colombiana de Historia, como la de caracterizar el país a la luz del marxismo, la militancia de izquierda, el compromiso político, la lucha de clases, la revolución..., puede significar algo del pasado, que no les dice mayor cosa; no me atrevería a afirmar que el creciente advenimiento de la historia cultural en el país es un problema de enfrentamiento generacional, pero algo de ello sí existe. Las nuevas generaciones de historiadores, ubicando el corte hacia I990, poseen un bagaje cultural y político distinto, quizá son más pragmáticos, menos soñadores y perfeccionistas.

Particularmente pienso que la parte dos, la de los debates, es la más enriquecedora, toda vez que los siete autores, en sus respectivos ensayos, presentan, desde sus experiencias investigativas, las "colaboraciones" con la historia cultural. El primer debate, a cargo de Mauricio Archila Neira, sobre los posibles encuentros y desencuentros de dos formas de hacer historia: la historia social y la historia cultural, muy emparentadas pero a la vez distantes. Para realizar su análisis hace un breve y sustancioso recorrido por ambas corrientes; a continuación revisa los encuentros y desencuentros de ambas. A partir de cuatro definiciones de lo que es la historia social, que dejan bien claro que esta es producto del desarrollo teórico e investigativo de la Escuela de los Annales y el marxismo inglés, cuyo comienzo se ubica en la década de los años veinte del siglo pasado, muestra cómo la llamada Nueva Historia cultural debe su nacimiento y desarrollo a la vertiente de la historia de la vida cotidiana, lo que permitió un tránsito, no traumático, de la historia social a la cultural. Analiza el enfoque interdisciplinario de la historia cultural pero, a la vez, coloca sobre el tapete uno de sus grandes problemas: lo impreciso de la definición de cultura, en realidad existen más de setecientas definiciones, lo que lleva a su banalización o a lo que el profesor Renán Vega llamó, en su reseña sobre el libro Puertos, sociedad y conflicto en el Caribe colombiano, I850-I93o de Sergio Paolo de las Aguas, "Reconfortante historia de las luchas laborales en los puertos del Caribe colombiano", en el Boletín Cultural y Bibliográfico (vol. 42, núm. 69, 2005, págs. I 56-I59), una historia light, para "damas rosas", que según parece ha "molestado" a los cultores de la historia cultural. Al plantear los encuentros y desacuerdos entre ambas formas de hacer historia, Archila subraya lo inconveniente de la historia cultural por abandonar la investigación, análisis, y reconstrucción de la macrocausalidad, de las estructuras. Afirma que el programa de la historia social está agotado como tal, y el de la historia cultural está de capa caída, se están reconformando, pero lo complicado es que en Colombia, y el libro que se reseña es un claro ejemplo, ni la una ni la otra están agotadas, sus programas son demasiado útiles para el análisis de la historia colombiana.

El ensayo de Marta Cabrera analiza el punto de encuentro entre los estudios subalternos y la historia cultural, para ello hace un recuento de la trayectoria de los estudios subalternos, muy vinculados a la descolonización de la India, bastante alejados de los planteamientos gramscianos y de la antropología cultural, desarrollada de manera principal en Italia, derivada de estos. Ratifica los planteamientos de las "bondades" de la historia cultural y de los estudios culturales; al analizar los sectores populares en sus manifestaciones, formas de resistencia, sistemas de creencias y rescatar el papel de las clases sociales, de la estratificación y del conflicto social, introduce nuevos sujetos históricos y observa dinámicas en el ámbito de la cultura. El trabajo de Gilberto Loaiza Cano, pese a ser una defensa permanente de su producción intelectual, lo que lo hace odioso y satírico a veces, intenta analizar el confuso diálogo permanente que existe entre la historia intelectual y la historia cultural; en él deja claro, aunque se quedó corto, que entre ambas existen fronteras vaporosas y territorios inmensos. Ubica la historia intelectual como el estudio de individuos, de intelectuales; de hecho, Loaiza ha publicado importantes estudios sobre los intelectuales colombianos decimonónicos, Luis Tejada (I995) y Manuel Ancízar (2004), concentrada en el mundo de las élites, de grupos de individuos sociohistóricamente diferenciados. Mientras que la historia cultural centra sus investigaciones, análisis y estudios en individuos y en comunidades humanas que, en términos generales, no detentan el poder, o no participan de un modo directo de él. Bien importante es su propuesta de adelantar biografías colectivas, como una forma de hacer historia cultural.

El ensayo de Renzo Ramírez Bacca establece una relación entre lo regional y lo cultural, a partir de intentar explicar porqué desde las localidades y regiones existen "identidades", "culturas", "tradiciones" e "idiosincrasias" diferentes y porqué tienen importancia sus representaciones históricas; con tal fin adelanta una reflexión sobre la región y las múltiples posibilidades que ella tiene para el análisis e investigación histórica e interdisciplinaria, y sobre todo en lo cultural, teniendo en cuenta que las regiones culturales también se convierten en "espacios de identidad". Por su parte, el ensayo de la profesora Stefania Gallini se centra en la historia ambiental, modalidad histórica que, al igual que la historia cultural, se inicia después de la revolución de mayo de I968; esta concibe el medioambiente como un protagonista importante del devenir humano, al final de cuentas 
en muchas de las acciones existentes sobre cultura se considera que ella es el proceso de transformación de la naturaleza para su bien, lo que ha permitido un diálogo permanente con la historia cultural y con otras disciplinas tanto sociales y humanas, como naturales, específicamente en las temáticas del consumo y los paisajes. El escrito de Stefan Pohl-Valero está encaminado a mostrar las perspectivas culturales para hacer historia de la ciencia en Colombia; parte de la historia cultural de la ciencia, que pretende entremezclar el análisis del discurso, metodología muy utilizada por la historia cultural, con el de la realidad social y de la naturaleza. Como en los otros ensayos, hace un recorrido por los autores, las teorías, etc., que han contribuido a conformar el actual cuadro epistemológico y metodológico de análisis y estudio de la historia de la ciencia.

El ensayo de Heraclio Bonilla establece las estructuras sociales de la economía, centrado en el análisis de la moneda como institución en el mundo andino. Inicia en lo que él llama una anomalía, pues en la época precolombina en esta región del mundo lo predominante fue una economía de autosuficiencia, mediante el control vertical de un máximo de pisos ecológicos, manejo que aún hoy subsiste en las regiones andinas del sur, lo que pese a ser una expresión de extrema pobreza, es una práctica que obedece a una realidad distinta: no responde a la obtención de ganancias, sino a la seguridad económica. Da un verdadero "paseo" por la teoría económica y en especial de la antropología económica para explicar el funcionamiento de la oferta, la demanda, y el intercambio, dentro de sociedades no "occidentales", también llamadas "primitivas". La indudable trayectoria de Bonilla en la temática de la economía andina, y su ya consolidado conocimiento de la colombiana, le permite plantear posibles y necesarias investigaciones en torno a la racionalidad económica engarzada con la cultura.

El epílogo, encargado a Francisco A. Ortega Martínez centra su atención en la renovada atención en los sucesos, en los acontecimientos, propios de la historia cultural,y el "distanciamiento" de esta de la larga duración. Afirma que el acontecimiento ha emergido, en los últimos treinta años, como una categoría analítica importante para el análisis social, en lo que, según la experiencia del autor en la temática de la Independencia, es importante el examen de los debates de prensa, las representaciones y memorias y las polémicas, en un lapso claramente delimitado. Propone una vuelta al estudio de los eventos y acontecimientos del periodo de la Independencia, lo que permitiría hacer una historia cultural y una nueva historia política.

Finalmente, al comienzo de esta reseña se hizo mención del interés de la historia cultural por escribir una historia diferente, más literaria, agradable y menos "ladrilluda". En el presente libro encontramos algo distinto; en efecto, si tenemos en cuenta que los ensayistas de la primera parte son cultores de la historia cultural, su lectura resulta tediosa a veces, todavía persiste en ellos el apego a elaborar sofisticados marcos teóricos para a su luz analizar el caso concreto, pero la redacción de algunos es demasiado complicada y por momentos queda cierta sensación de una "indigestión" de autores, sin mayor elaboración y fluidez.

\section{José Eduardo Rueda Enciso}

Profesor titular,

Escuela Superior de Administración Pública 